\title{
Concerns with Current Approach to Competency Based Medical Education of EM Specialists
}

To the editor: We applaud Dr. Jonathan Sherbino and colleagues for their excellent overview in the January 2020 issue of CFEM, titled, "The competency-based medical education evolution of Canadian emergency medicine specialist training." 1 Competency-based medical education (CBME) is undoubtedly the most significant transformation of the Fellow of The Royal College of Physicians of Canada-Emergency Medicine (FRCPC-EM) program since its inception, and this paper on its genesis and specifics is timely. We were also pleased to see the paper made reference to the work of the Collaborative Working Group in Emergency Medicine in Canada (CWG-EM), a trilateral 3-year initiative we participated in involving the Canadian Association of Emergency Physicians (CAEP), the College of Family Physicians of Canada, and the Royal College that led to a comprehensive final report in June 2016. ${ }^{2}$

The unprecedented national surveys of emergency physicians and residents undertaken by the CWG-EM indicated that a "substantial proportion of respondents report discontent regarding the current approach to EM training and care in Canada." ${ }^{2}$ As detailed in the CWG-EM final report, this discontent included concerns regarding the efficiency and effectiveness of both Canadian EM training programs, and it led to a number of explicit recommendations. Specific to the Royal College, the CWG-EM felt that CBME "can address concerns related to the FRCPC-EM program." Central to those concerns were the lack of mandated direct exposure to family medicine and the 5-year length of the Royal College program for all residents, regardless of their future career inclinations.

The CWG-EM raised concerns that, during the Royal College EM training program, there was limited exposure of residents to "aspects of clinical family medicine, specifically, transitions of care and community care." The final report recommended, "In this transition to CBME, the Royal College should review the current FRCPC-EM curriculum and incorporate increased competencies relating to the relationship of emergency and primary care and the larger continuum of care external to the ED setting." It is disappointing that meaningful changes related to this have yet to be implemented.

Dr. Sherbino and colleagues correctly note that "competency-based medical education opens up the possibility of shorter training time." While this statement is hypothetically true, in practice, as it relates to the current structure and sequencing of CBME in the Royal College EM training program, it appears all but impossible for anyone to exit in fewer than 5 years. In large part, this arises because of the requirement that all residents pursue, early in their training, an "area of concentrated expertise" (the range of options for which are virtually limitless) regardless of their future practice inclinations. While we agree with Dr. Sherbino and colleagues that individuals undertaking such training "improves the quality of Canadian emergency health systems," this does not mean it is an optimal use of scarce training resources to mandate all residents do so. Nor is doing so consistent with the CWG-EM principle that both colleges must match the training of their residents to their future intended practice.

We believe the Royal College EM Specialty Committee has a fiduciary responsibility to consider both fiscal efficiency and residents' specific training needs as it advances CBME. The work of the CWGEM clearly indicates that many FRCPC-EM graduates practise predominantly clinical EM, and thus the training of such individuals should be tailored to this; and an optimal CBME system would allow an earlier exit than required for residents with special competency or subspecialty

Correspondence to: Dr. Doug Sinclair, IWK Health Centre, 5850/5980 University Ave, Halifax B3K 6R8, Canada: Email: douglas.sinclair@iwk. nshealth.ca

(c) Canadian Association of Emergency Physicians 2020 
inclinations, thus freeing up more resources to train others.

The CWG-EM projected a health human resources shortfall of 1,518 emergency physicians in Canada by 2025 . It behooves our leaders in both Canadian EM training programs to continue to evolve and collaborate to address this and optimize use of our scarce training resources. Doing so should include continued reference to and tracking of progress related to the CWG$\mathrm{EM}$ recommendations, as these were supported by our data, the members of the CWG-EM, and the three associations we collectively represented.
Doug Sinclair, MD

Past Chair Collaborative working group on the Future of Emergency Medicine in Canada

Riyad B. Abu-Laban, MD, MHSc

Past CAEP Representative \& Member Collaborative working group on the Future of Emergency Medicine in Canada

Peter Toth, MD

Past CAEP Representative \& Member Collaborative working group on the Future of Emergency Medicine in Canada
Keywords: Education, residents and fellows

Competing interests: None declared.

\section{REFERENCES}

1. Sherbino J, Bandiera G, Doyle K,. The competency-based medical education evolution of Canadian emergency medicine specialist training. CFEM 2020;22(1):95-102.

2. Canadian Association of Emergency Physicians (CAEP). Collaborative Working Group on the future of emergency medicine in Canada. Final report of the Collaborative Working Group on the future of emergency medicine in Canada; 2016. Available at: https:// caep.ca/advocacy/collaborative-working-group-final-report/ (accessed March 2, 2020). 